\title{
How Organizational Support Can Cultivate a Multilevel Safety Climate in the Construction Industry
}

DOI:

10.1061/(ASCE)ME.1943-5479.0000758

\section{Document Version}

Accepted author manuscript

Link to publication record in Manchester Research Explorer

\section{Citation for published version (APA):}

Cheung, C., \& Zhang, R. P. (2020). How Organizational Support Can Cultivate a Multilevel Safety Climate in the Construction Industry. Journal of Management in Engineering. https://doi.org/10.1061/(ASCE)ME.19435479.0000758

\section{Published in:}

Journal of Management in Engineering

\section{Citing this paper}

Please note that where the full-text provided on Manchester Research Explorer is the Author Accepted Manuscript or Proof version this may differ from the final Published version. If citing, it is advised that you check and use the publisher's definitive version.

\section{General rights}

Copyright and moral rights for the publications made accessible in the Research Explorer are retained by the authors and/or other copyright owners and it is a condition of accessing publications that users recognise and abide by the legal requirements associated with these rights.

\section{Takedown policy}

If you believe that this document breaches copyright please refer to the University of Manchester's Takedown Procedures [http://man.ac.uk/04Y6Bo] or contact uml.scholarlycommunications@manchester.ac.uk providing relevant details, so we can investigate your claim.

\section{OPEN ACCESS}




\title{
How Organizational Support Can Cultivate a Multilevel Safety Climate in the Construction Industry
}

\author{
Dr Clara Man Cheung ${ }^{1}$, Dr Rita Peihua Zhang ${ }^{2}$ \\ ${ }^{1}$ Lecturer, School of Mechanical, Aerospace, and Civil Engineering, University of Manchester, George Begg Building, \\ Manchester, M1 3BB, United Kingdom, clara.cheung@manchester.ac.uk \\ ${ }^{2}$ Senior Lecturer, School of Property, Construction and Project Management, RMIT University, GPO Box 2476, Melbourne \\ VIC 3001, Australia, rita.zhang@ rmit.edu.au
}

\begin{abstract}
Safety climate has a positive impact on safety performance in the construction industry; it is a multilevel phenomenon that can be formed at organization and group levels especially in large organizations with multilevel management structure. The study investigates how organizational support cascades down to cultivate group-level safety climate at two time points over a two-year period through the relationship with organization-level safety climate, supervisory safety-specific transformation leadership, and co-worker support in a large US-based construction contractor.
\end{abstract} Structural equation modeling analysis on data from an online survey among 284 construction professionals shows, different from prior research, that organizational support at one point in time does not directly predict subsequent group-level safety climate. Instead, it affects group-level safety climate through the mediation effect of supervisory safety-specific transformation leadership and organizational-level safety climate, and its moderation effect on the relationship between co-worker support and group-level safety climate. Importantly, the results also suggest that safety-specific transformational leadership may be an even more important predictor of group-level safety climate than organizational-level safety climate and co-worker support. These results imply that organizations support could focus on empowering leaders to demonstrate safety-specific transformational leadership behaviors for the sake of enhancing group-level safety climate.

\section{KEYWORDS}

Organizational support, safety climate, safety-specific transformational leadership, co-worker support, structural equation modeling 

fatalities were in construction, accounting for $20.7 \%$ of the overall work-related fatal injuries in the United States (U.S. Bureau of Labor Statistics [BLS], 2017). These numbers are disproportionally high given that the construction workforce made up less than $7 \%$ of the overall total employment in the US (The Center for Construction Research and Training, 2017). In spite of technological developments and the implementation of vigorous health and safety management systems, the chronic level of fatalities, serious injuries, and ill-health in the construction industry seem to be resistant to change. This has led researchers and practitioners to look into organizational and psychological factors including safety climate that could drive positive change in the industry's notorious health and safety performance.

Safety climate describes employees' perceptions of the value of safety in their workplace. It was originally defined by Zohar (1980, p.101) as "a unified set of cognitions regarding the safety aspects of the organization" which "reflects employees' shared perceptions about the relative importance of safe conduct in their occupational behavior". Since the 1990s, safety climate has often been at the centre of safety research because there is considerable evidence that positive safety climates are linked to improved safety behaviour and/or performance within organizations across different industries. For instance, Dahl and Kongsvik (2018) reported that safety climate positively predicts workers' mindful safety practices in the Norwegian oil and gas industry. Mindful safety practices reflect workers' ability of identifying critical factors in the work environment and acting appropriately if dangers arise (Dahl \& Kongsvikm 2018). Through a meta-analysis, Alruqi et al. (2018) identified those safety climate dimensions (e.g. management commitment and supervisor safety roles) that are consistently related to self-reported injuries and/or recorded injury rate in the construction industry. Curcuruto et al. (2018) found that safety climate is positively associated with workers' safety attitude and behaviour but negatively related to accident-related indices in the UK rail industry. 
construction have focused on the organization as the unit of analysis (e.g., He et al.,2016). Yet, organizations are social systems that are constructed through interdependencies between individuals and subunits across an organizational hierarchy (Kozlowski \& Klein, 2000). This hierarchy creates micro- and macro-levels of safety climate. Consistent with the idea that organizations are multilevel systems, Zohar and Luria (2005) proposed and tested a multilevel model of safety climate that includes organization-level and group-level safety climate in a manufacturing context. Organizationlevel safety climate (OSC) arises from the formal organizational-wide policies and procedures imposed by top management, while group-level safety climate (GSC) arises from the safety practices associated with the implementation of organizational policies and procedures by front-line supervisors in each workgroup. In particular, Zohar and Luria (2005) proved that OSC and GSC are two distinguishable constructs. Further, the researchers found that the positive effect of OSC on safety behaviors is fully mediated by GSC. The results provided a new multilevel approach to investigating safety climate.

In support of multilevel safety climate investigation, a few studies in the construction industry have been conducted. Lingard et al. (2010) tested the multilevel safety climate model in the Australian construction industry. They found that the subcontractor's group-level safety climate (GSC) is positively predicted by the principal and subcontractor's organization-level safety climate (OSC) at a large building construction project in Melbourne. In addition, the subcontractor's GSC is a significant predictor of the rate of lost-time and medical treatment incidents. Following this, Lingard et al. (2012) extended the multi-level safety climate study to three Australian construction organizations, and found that GSC fully mediated the relationship between OSC and workgroup injury frequency rate. Similarly, Gao et al., (2016) investigated multilevel safety climate in Vietnam's construction industry and reported consistent results, i.e. OSC is positively and significantly related to GSC, while GSC partially mediates the relationship between OSC and safety performance.

Overall, the positive relationships between multilevel safety climate and safety performance have been well established in the literature, but limited research has focused on the antecedents, 
mediators and moderators of multilevel safety climate (Zohar, 2010). This knowledge gap leads to a lack of insights into how organizations should foster a positive safety climate. Among the limited research, several studies found that organizational support is critical of driving safety climate (Wallace et al., 2006; Gyekye and Salmine, 2007; DeJoy et al., 2010) because it demonstrates the priority of safety to employees, which leads to the formation of a positive safety climate. In addition, research indicates that workers' perceptions of safety environment in the local workgroup are constructed through social interactions between workers and their supervisors as well as co-workers (Brondino et al. 2012). Supervisory safety leadership and co-workers' safety response are important sources for workers to ascertain safety value and priority in the workgroup (Zhang et al., 2015). However, the underlying mechanism of the relationships between multilevel safety climate and organizational support is unclear. Further, most of the existing studies of multilevel safety climate were conducted in non-construction industries using cross-sectional design. As a result, the applicability to the construction industry and direction of causal relationships have not been well established. This missing piece of information would hinder construction organizations in improving their levels of safety climate in more targeted and effective ways.

To address these limitations, this study examines how organizational support cascades down to cultivate group-level safety climate (GSC) through the mediation role of organization-level safety climate (OSC) and supervisory safety-specific transformation leadership (SSTL), and the moderation effect with co-worker support (CS) in a large construction contractor at two time points over a 2-year period. In the following sections, these constructs and a model of relationships among these constructs are presented.

\section{Literature Review and Hypothesized Model}

\section{Safety climate}

Zohar (1980, p. 96) firstly defined safety climate as "a summary of molar perceptions that employees share about their work environments". Later Neal and Griffin defined safety climate as "individual perceptions of policies, procedures, and practices relating to safety in the workplace" 
111 (Neal and Griffin, 2006, p. 947). Safety climate reflects employees' perceptions of their organization 112 priority placing on safety relative to other goals (e.g. production) (Zohar, 1980).

Safety climate is closely related to but theoretically different from another frequently mentioned concept, i.e. safety culture. Guldenmund (2000, p.251) defined safety culture as "those aspects of the organizational culture which will impact on attitudes and behaviors related to increasing or decreasing risk". This definition imply that safety culture is an integral part of organizational culture. Grounded in the organizational culture model by Schein's (1985), Glendon and Stanton (2000) proposed that cultural influences on safety can be manifested at three levels: 1) at the deepest level, the basic assumptions underlying the operation of an organization influences all aspects of the organization, including safety; 2) at the intermediate level, the beliefs and espoused values held by organizational members regarding safety have a safety impact; 3 ) at the surface level, safety related behaviors and artefacts, such as safety policy, rules and procedures and supervisory actions, are the most evident indication of cultural influences on safety. The basic assumptions are so deeply embedded that they are very difficult to be explicitly articulated by individuals who hold such assumptions (Guldenmund, 2000). However, the two outer layers (i.e. the beliefs and espoused values, and the behaviors and artefacts), which are rooted in the basic assumptions, can be revealed through measuring workers' attitudes and perceptions (Guldenmund, 2000). Researchers have generally recognized that the two outer layers relating to safety are reflected in safety climate (Glendon and Stanton, 2000; Guldenmund, 2000). In other words, safety climate is the surface reflection or a snapshot of safety culture.

As noted earlier, safety climate is a multilevel construct which can be formed at two different levels, i.e. at the organizational level and the group level (Zohar, 2000; Zohar and Luria, 2005). This proposition is based on the assumption that formal policies and procedures are established by top management at the organizational level and are executed by supervisors at the group level. During the execution process, supervisors are likely to interpret the formal procedures and turn the formal procedures into situation-specific action directives in different ways. This then leads to different perceptions of supervisory practices developed by workers of different sub-groups. The multilevel 
safety climate model has received recognition in the construction industry, where construction organizations are large and complex with decentralized structures, and non-routine construction work is undertaken by semi-autonomous work groups (Zhang et al. 2015). Frontline employees normally have few opportunities to directly interact with the top management of their organizations. However, they have frequent interactions with supervisors who give them daily guidance and instruction. Zohar and Luria (2005) argue that shared expectations associated with supervisory practices act as a more powerful or proximal antecedent to workers' safety behavior than organization-level expectances.

The importance of safety climate lies in shaping workers' behaviors through the perceptions formed about how safety is rewarded and supported by their organizations (Lingard et al. 2012).

Driven by this expectation, safety climate research is receiving increasing interest in the construction industry. Evidence regarding the positive associations between safety climate and various aspects of safety performance has been reported across countries. Specifically, Pousette et al. (2008) reported that safety climate significantly predicted self-reported safety behavior within a major tunnel project in the Swedish construction industry. Chen et al. (2017) found that safety climate directly influences workers' safety behaviors and physical health, and indirectly influences workers' psychological wellbeing in the Canadian construction industry. Emerging research evidence also suggests that safety climate can be considered as a valid leading indicator, i.e. safety climate measured at one point in time predicts the occurrence of accidents or injuries at a future point in time (e.g., Wallace et al., 2006).

\section{Organizational support (OS) and safety climate}

Organizational support (OS) theory suggests that employees form beliefs about the degree to their organization values their contribution and cares about their well-being (Eisenberger et al. 1986). These beliefs can be general or specific to a certain organizational aspect (Tucker et al. 2008). In this study, organizational support for safety is the primary focus. It is natural and sensible to think that if an organization strongly supports safety, it would develop effective safety policies and procedures to maintain high safety standards, as well as require frontline management to effectively enforce the safety policies and procedures for creating a safe workplace. This subsequently shapes employees' perceptions about the importance ascribed to safety at their workplace, leading to the formation of 
positive perceptions of safety climate. Corroborating this reasoning, DeJoy et al. (2004) found that organizational support has a positive association with safety climate. Furthermore, social exchange theory may provide an additional lens for understanding this association. Social exchange is driven by the norm of reciprocity (Blau, 2017), i.e. one party's favor leads to another party's obligation to return the favor with some form of positive action. As applied to work environments where safety is a concern, if employees perceive that their organizations support safety, emphasize the importance of safety, and take actions to ensure employees' health and safety, they will reciprocate with more positive safety-related perceptions and behaviors. Grounded in social exchange theory, Mearns and Reader (2008) identified a positive relationship between perceived organizational support and employees' safety perceptions.

Positive links between organizational support and perceptions of safety climate at both organizational and group levels have been evidenced in many studies. For instance, Wallace et al. (2006) found that organizational support affects group-level safety climate (GSC) and subsequently accidents. DeJoy et al. (2010) discovered that perceived organizational support predicts perceptions of organizational-level safety climate (OSC). As a result, it affects how people perceive safety at work. Gyekye and Salmine (2007) reported that workers with higher perceptions of organizational support reported more positive perceptions of safety climate at various organizational levels. All these findings affirm that employees' beliefs about organizational support for safety generate their positive perceptions about how safety is valued in their organization and implemented in the workplace. Therefore, it is hypothesized that:

H1: Perceived organizational support (OS) directly predicts group-level safety climate (GSC). H2: Perceived organizational support (OS) directly predicts organization-level safety climate (OSC).

\section{Organization-level safety climate (OSC) and group-level safety climate (GSC)}

Zohar and Luria (2005) suggested that although supervisory discretion leads to variations among groups, the differences could be limited. The reason is that the policies and procedures created 
at the organizational level have set the boundaries for permissible group-level interpretations.

Supervisors are expected to implement the policies and procedures within their workgroups but not redefine them (Zohar and Luria, 2005). In this sense, organization-level safety climate (OSC) and group-level safety climate (GSC) should be generally aligned, suggesting that the OSC predicts GSC (Zohar and Luria, 2005). In line with this proposition, Huang et al. (2017) found that OSC and GSC are strongly and positively interrelated, and also work together in a supplementary manner in promoting safe behaviors. The positive relationship between organization-level safety climate and group-level safety climate has also been proved by previous literature in the construction industry (e.g., Cheung et al., The influence of safety leadership, social support and psychological capital on construction safety climate, unpublished report; Lingard et al. 2012). Based on the research evidence, it is therefore hypothesized that:

H3: Organization-level safety climate (OSG) directly predicts group-level safety climate (GSC).

Taking Hypothesis 2 and Hypothesis 3 into account together, it is logical to assert that strong organizational support (OS) for safety positively affects employees' perceptions on how their organization prioritizes safety matters, which forms a positive organizational safety climate (OSG). A high level of OSG subsequently imposes high expectations on supervisors in terms of safety enforcement and establishing a high safety priority within their workgroups, which then leads to the formation of high levels of group-level safety climate (GSC). Therefore, OSC could act as a mediator between OS and GSC. It is thus hypothesized that:

H4: Organization-level safety climate (OSC) mediates the relationship between organizational support (OS) and group-level safety climate (GSC).

\section{Supervisory safety-specific transformational leadership (SSTL), organizational support}

\section{(OS) and group-level safety climate (GSC)}

In recent years, it has been a growing interest in the effect of supervisory leadership behaviors on various safety-related outcomes (e.g. Barling et al. 2002; Mullen and Kelloway, 2009; Willis et al., 
2017). In particular, transactional leadership and transformational leadership are two leadership styles that have been extensively studied in the existing safety leadership literature. Based on Bass (1985), transformational leaders engage subordinates by making them more aware of the meaning of work, by activating their higher-order needs, and by inducing them to transcend self-interest; while transactional leaders identify actions to be taken to obtain desired goals, set clear job requirements, and develop management systems related to those goals.

Research evidence has shown that transformational and transactional leadership styles positively influence safety in various ways. For example, through a meta-analysis, Clarke (2013) demonstrated that while transformational leadership has a positive impact on safety climate and safety participation behaviors, active transactional leadership has strong and positive associations with safety climate and safety compliance behaviors. Hoffmeister et al. (2014) found that although the transformational leadership dimensions of idealized attributes and idealized behaviors emerged as consistently important predictors of multiple safety outcomes, the transactional leadership aspect of contingent reward also explained a non-trivial proportion of variance in the safety outcomes.

Similarly, Zohar (2002b) reported that transformational leadership and transactional contingent reward predict injury rates in organizational subunits, with the effect mediated by safety climate. Therefore, Zohar (2002b) argues that both transformational and transactional leadership styles are important to ensure optimal safety performance.

Consistent with Zohar's line of thought, Barling et al. (2002) suggested and validated the construct of safety-specific transformational leadership (SSTL). It consists of four components of transformational leadership (i.e. idealised influence, inspirational motivation, intellectual stimulation, and individualised consideration) and the transactional leadership aspect of contingent reward. Leaders who demonstrate SSTL should "take an active and inspirational approach to safety issues, serving as good models of safety behavior and encouraging others to work in a safe manner" (Kelloway et al., 2006, p78).

Studies of organizational behavior have indicated that supervisors are more likely to develop high quality exchange relationships with subordinates if they perceive organizational support (Erdogan 
\& Enders 2007). In the context of safety, it is also expected that organizational support can influence supervisory safety leadership. According to role theory, safety support or expectations communicated by top management provides guidance to supervisory roles relating to safety (Zohar, 2002b). If top management conveys the message that they support safety and place a high priority on safety, supervisors are likely to demonstrate stronger transformational leadership, i.e. engaging in more positive interactions and developing higher quality relationships with subordinates, as well as showing greater concern for subordinates' welfare (Zohar, 2000b). In the construction industry, Conchie et al. (2013) conducted focus groups with construction supervisors in the UK and reported that organizational support for safety is a critical motivator for supervisors to engage in safety leadership. In their study, one example of organizational support was related to the implementation of a behavioral change program by a few companies to promote a positive safety culture. This supportive initiative motivated supervisors to better engage in safety leadership in various ways, such as by conveying the message that safety is a high priority in the organization and expected to be fostered as (SSTL). Zohar (2002a) argues that a supervisor's leadership behavior provides an important source of information for group members to ascertain the overall priority that the supervisor puts on safety. This priority then partly affects subordinates' perceptions of safety climate in workgroups. Compelling occupational injuries through the mediating effects of perceived safety climate and safety-related events. This model was then replicated and extended in Kelloway et al. (2006), who also reported that addition, Mullen and Kelloway (2009) demonstrated that providing managers with safety-specific 
transformational leadership training resulted in improvements in workers' perceptions of safety climate and other safety outcomes. Based on the previous literature, it is hypothesized that:

H6: Supervisor's safety-specific transformational leadership (SSTL) predicts group-level safety climate.

Taking Hypothesis 5 and Hypothesis 6 into account together, it is logical to assert that organizational support (OS) facilitates supervisors in better engaging in safety-specific transformational leadership (SSTL) behaviors, which in turn positively cultivate group-level safety climate (GSC). Therefore, SSTL could be a mediator between OS and GSC. It is thus hypothesized that:

H7: Supervisory safety-specific transformational leadership (SSTL) mediates the relationship between organizational support (OS) and group-level safety climate (GSC).

\section{Co-worker support (CS) and group-level safety climate (GSC)}

Lingard et al. (2011) claimed that apart from individuals with formal power (e.g. top managers, supervisors); those who do not possess formal power (e.g. co-workers) can also influence values and norms in workgroups. Situated in the framework of social exchange theory, Tucker et al. (2008) identified a positive link between perceived co-worker support for safety and employee safety voice. Specifically, when workers receive information about hazards or safety concerns from coworkers, the norm of reciprocity makes them feel obligated to engage in safety behaviors, such as reporting unsafe working conditions and making safety suggestions. Based on social learning theory and social information processing theory, Turner et al. (2010) argue that when others in the work environment support safety, they reinforce the importance of safe work practices and provide social cues that employees are expected to maintain a safe work environment. Particularly, the researchers revealed that co-worker support for safety is the most critical factor in keeping workers safe while under the pressure of other job performance demands. Co-worker support has also been found to be associated with individual positive perceptions of safety climate (Gillen, et al. 2002). Brondino et al. (2012) argued that safety climate within workgroups is constructed through social interactions 
between individuals, not only between workers and supervisors but also between co-workers. It is through the frequent interactions between co-workers that individuals develop their beliefs about what is expected in the work environment (Chiaburu and Harrison, 2008). Therefore, it is hypothesized that: H8: Co-worker support (CS) for safety predicts group-level safety climate (GSC).

\section{Organizational support (OS) as a moderator}

Workgroups are hierarchically nested within an organization. It is anticipated that the broader contextual factors (e.g. organizational support) at the organizational level have an impact on the dynamics and practices within workgroups. Despite top management normally being physically away from front-line exercises and rarely having direct interactions with front-line employees, they are able to influence group safety norms related to co-worker support for safety through demonstrations of supportive actions on safety issues (Tucker et al. 2008). Consistent with social exchange theory, if employees perceive that their organizations support and care about their safety, they will feel obligated to reciprocate with more positive actions, such as showing concern and support toward workmates that contribute to a safer workplace. In addition, Dierdorff et al. (2009) argued that role fulfilment (e.g. managerial role or team member role) is shaped by contextual factors, and individual role interplays with the contextual environment in which it is performed. This suggests an interactive effect of organizational support and co-worker support on the perceptions of group-level safety climate. Therefore, it is hypothesized that:

H9: Organizational support (OS) for safety moderates the relationship between co-worker support (CS) for safety and group-level safety climate (GSC).

Based on the proposed research hypotheses, the presented work hypothesizes a model to explore how organizational support cascades down to cultivate group-level safety climate directly and indirectly through the mediation effect of organization-level safety climate and supervisory safetyspecific transformation leadership, as well as through moderating the relationship between co-worker support and group-level safety climate. 


\section{Variables}

The hypothetical model contains five latent variables. Each variable was measured by psychometrically validated measurement scales with a total of 48 measure items listed in Table 1 . The three items for measuring organizational support (OS) and three items for measuring co-worker support (CS) were extracted from the study by Mueller et al. (1999). The 16 items for measuring organizational-level safety climate (OSC) and 16 items for measuring group-level safety climate (GSC) were derived from the study by Zohar and Lucia (2005). The 10 items for measuring safety specific transformational leadership (SSTL) were developed by Barling et al. (2002). In addition to the five variables, social desirability was measured using the 5-item Marlow-Crowne Social Desirability Scale (Strahan \& Gerbasi, 1972). All the items were measured using a five-point Likert scale where "1" represents strongly disagree/not at all and "5" presents strongly agree/always.

[Table 1. Measurement scales]

\section{Sample and Procedure}

The surveys were completely anonymous and voluntary and were completed by construction professionals who worked at a large US-based construction contractor, which works for commercial and civil projects with annual revenue over $\$ 5$ billion. The company has business units and construction projects across the US. A single large organization was selected for the study as it enables researchers to investigate how organizational support imposes cascading influence on multi-level safety climate by restricting variations due to intra-organizational differences such as culture and structure. Yet, the limitations of the design are illustrated in the later section. Participants were selected based on the criteria that they were working in at least one construction site and having a supervisor. Using these criteria, 619 questionnaires were distributed using email in 2016 (Year 1), and in 2017 (Year 2). In 2016, employees completed a measure of social desirability, which was used to control for potential common method variance, as well as the measure of organizational support (OS) and co-worker support (CS). In 2017, participants responded to items concerning safety specific 
transformational leadership (SSTL), organizational-level safety climate (OSC), and group-level safety climate (GSC). 383 staff completed the first survey (a 62\% response rate), and 332 staff completed the second survey (a 54\% response rate). Both of the two surveys were completed by a longitudinal sample of 292 employees. By eliminating missing values, the total usable samples are 284 , which appear favorable for structural equation modeling (SEM) analysis that requires a minimum of 200 responses (Kline, 2015). According to the statistical analysis on the usable samples as shown in Figure 1, 56\% respondents worked in the construction industry for over 15 years, $26 \%$ worked at the company for over 15 years, $73 \%$ completed a Bachelor's degree or above, and $91 \%$ were male. In general, the majority of the respondents were familiar with the construction industry based on their long service time, which increased the quality of the survey data and the persuasiveness of the following analysis results to some extent.

[Fig. 1. Statistics on respondents]

\section{Data Analysis}

To test the hypotheses, structural equation modeling (SEM) was employed. SEM combines multiple statistical methods including factor analysis, multiple correlation analysis, multiple regression, and path analysis. SEM fits the objective of this the study because: (1) it handles underlying relationships between latent variables and their measure items; (2) it estimates interrelated dependence relationships among latent variables in the hypothesized model; (3) it measures estimation errors; and (4) it explains an entire set of relationships as a holistic model. Due to these advantages, SEM has been widely used in social science studies for testing causal relationships (Kline, 2015).

In practice, SEM contains two major components: the measurement model and the structural model. The measurement model is tested using a confirmatory factor analysis (CFA) which examines the covariance among latent variables and their measure items. The structural model is assessed using a path analysis that evaluates the associations and possible causal relationships among latent variables. Both the measurement and structural models are validated through testing the goodness of model fit. Three groups of goodness-of-fit indices and associated thresholds are recommended by Kline (2015) 
and Hooper et al. (2008) for assessing model fit. The first group consists of absolute fit indices, including values from a $\chi 2$ test [ideal threshold $<0.05$ ], Root Mean Square Error of Approximation (RMSEA) [ideal threshold <0.080], and Root Mean Square Residual (RMR) [ideal threshold <0.050]. The second group is comprised of incremental fit indices, including Comparative Fit Index (CFI) [ideal threshold $>0.900]$ ), Normed Fit Index (NFI) [ideal threshold > 0.700]), Incremental Fit Index (IFI) [ideal threshold > 0.900]), and Adjusted Goodness-of-Fit Index (AGFI) [ideal threshold > 0.700]. The last group consists of parsimonious fit indices, including Parsimonious Normed Fit Index (PNFI) [ideal threshold > 0.500], Parsimony Goodness-of-Fit Index (PGFI) [ideal threshold > 0.500]), and Parsimony Comparative Fit Index (PCFI) [ideal threshold > 0.500]. The outputs of SEM are a set of exogenous and endogenous variables, the correlations among the variables, and the path coefficients between the variables. In this study, SPSS AMOS 24 software was used to conduct the SEM analysis.

\section{MEASUREMENT MODEL}

The measurement model was validated using confirmatory factor analysis (CFA) in which construct validity and goodness of model fit were examined. Construct validity consists of two components, namely convergent validity and discriminant validity.

\section{Convergent validity}

Convergent validity means the items of a specific latent variable should share a high proportion of variance in common (Hair et al., 2013), indicating internal consistency reliability. The Cronbach's alpha, composite reliability (CR) and average variance extracted (AVE) were used to examine convergent validity in this study. As shown in Table 2, the Cronbach's alphas of each variable were above the recommended threshold of 0.700 (Fornell \& Larcker, 1981). The CR for each of the variables was greater than the recommended threshold of 0.700 (Hair et al., 2013). Furthermore, the AVE for each of the variables was above the recommended threshold of 0.500 (Kline et al., 2015). All the above results indicate that the measurement model obtained sufficient convergent validity.

\section{Discriminant validity}


variable is distinct from other variables, existing as a unique variable (Hair et al., 2013). It is typically

403

404

405

406

407

408

409

410

411

412

413

414

415 assessed by comparing the square root of AVE for any two constructs with the correlation estimates between these two constructs. The square root of AVE estimates should be larger than the correlation estimate. The logic is that a latent variable should explain more of the variance in its own items than it shares with another construct (Hair et al., 2013). As shown in Table 2, the square root of each AVE value on the diagonal highlighted in bold is higher than the correlation estimates below it, indicating that the measurement model obtained sufficient discriminant validity. Therefore, all variables are unique and distinct from one another.

\section{Goodness of Model Fit}

Table 3 illustrates that the measurement model achieved a good model fit as all the values for goodness of fit indices passed the necessary thresholds: $\chi 2$ test $=0.000 ;$ RMSEA $=0.060 ; \mathrm{RMR}=$ $0.030 ; \mathrm{CFI}=0.910 ; \mathrm{NFI}=0.837 ; \mathrm{IFI}=0.910 ; \mathrm{AGFI}=0.748 ; \mathrm{PNFI}=0.856 ; \mathrm{PGFI}=0.788 ; \mathrm{PCFI}=$ 0.856. .

[Table 3. The results of goodness-of fit verification of the measurement model]

\section{Common Method Bias (CMB)}

Since all the variables were collected via a single method (online survey), a CMB test was conducted to determine if a common factor may have been influencing the results. Generally speaking, social desirability has been widely proved to be a common factor that can produce spurious observed correlations between variables, thus leading to CMB (Donaldson \& Grant-Vallone, 2002). In particular, social desirability makes people under-report behaviors deemed inappropriate by others, and over-report behaviors viewed as appropriate. By collecting data on the Marlow-Crowne Social Desirability Scale (Strahan \& Gerbasi, 1972) in the online survey, the common latent factor (CLF) method (Podsakoff et al., 2003) was applied to disentangle social desirability from the independent and dependent variable in the measurement model in order to check the effect on composite reliability (CR) and average variance extracted (AVE) scores for each construct. The results as shown in Table 4 indicate that there are sufficiently strong CR and AVE scores of all the constructs as they are all above 
the recommended thresholds of 0.700 and 0.500 respectively. In addition, there were no differences greater than 0.05 comparing indicator loadings before and after adding the CLF. Thus, the measurement model is not significantly affected by common method bias.

[Table 4. The results of common method bias test of the measurement model]

\section{STRUCTURAL MODEL}

To test the hypotheses, a structural model was created and tested. Table 5 illustrates that all the values of goodness of fit indices were above thresholds, suggesting that the structural model achieved good model fit: $\chi 2$ test $=0.000$; Root Mean Square Error of Approximation $($ RMSEA $)=$ 0.056; Root mean square residual $(\mathrm{RMR})=0.044$; Comparative Fit Index $(\mathrm{CFI})=0.905$; Normed-Fit Index $(\mathrm{NFI})=0.817 ;$ Incremental Fit Index $(\mathrm{IFI})=0.905 ;$ Adjusted Goodness of Fit Index $(\mathrm{AGFI})=$ 0.747; Parsimony Normed Fit Index $(\mathrm{PNFI})=0.773$; Parsimony Goodness of Fit Index $(\mathrm{PGFI})=$ 0.700; Parsimony Comparative Fit Index $(\mathrm{PCFI})=0.856$. In addition, the total variance explained is satisfactory for the endogenous variables: $\gamma^{2}=56 \%$ for the group-level safety climate as show in Figure 3.

[Table 5. The results of goodness-of fit verification of the structural model]

\section{Direct Effect}

Table 6 and Figure 2 present the test results of the hypotheses in the structural model. The results identify five significant direct effects that support the research hypotheses $\mathrm{H} 2, \mathrm{H} 3, \mathrm{H} 5, \mathrm{H} 6$, and H8. Specifically, the significant direct effect of organizational support (OS) on organization-level safety climate $(\mathrm{OSC})(\beta=0.431, p<0.001)$ supports $\mathrm{H} 2$, suggesting that high levels of OS has a positive impact on OSC; the significant effect of OSC on group-level safety climate (GSC) ( $\beta=$ $0.307, p<0.001$ ) supports $\mathrm{H} 3$, suggesting that high levels of OSC has a positive effect on GSC; the significant effect of OS on supervisory safety specific transformational leadership (SSTL) supports H5 ( $\beta=0.425, p<0.001)$, suggesting that a high level of OS has a positive impact on SSTL; the significant effect of safety specific transformation leadership (SSTL) on GSC $(\beta=0.555, p<0.001)$ 
supports H6, suggesting that a high level of SSLT positively impacts GSC; and the significant effect of co-worker support (CS) on GSC $(\beta=0.271, p<0.001)$ supports $\mathrm{H} 8$, suggesting that a high level of CS. has a positive effect on GSC. Yet, the absence of a significant direct effect of OS on GSC leads to a rejection of $\mathrm{H} 1(\beta=0.061, p=0.465)$.

[Table 6. Test results of the hypotheses]

[Fig.2. Hypothesized model estimation results]

\section{Mediation}

A mediation effect is a mechanism in which one variable affects another one through a mediator variable. For example, in $\mathrm{H} 4$, the causal chain of effect from OS to OSC to GSC - the indirect effect — represents the mechanism through which OS's effect on GSC operates. In this study, mediation was tested using the bias corrected bootstrapping confidence interval technique on indirect effect as recommended by numerous statisticians (e.g., Hayes and Scharkow 2013; Williams and Mackinnon, 2008), instead of using the traditional Baron and Kenny approach (Baron and Kenny, 1986) and Sobel test (Sobel, 1986). This is because Haynes and Scharkow (2013) found that the bootstrapping technique provides the most trustworthy test results confirming the presence and degree of a mediation effect compared to the above two traditional methods. Although the Baron and Kenny approach has been widely used, it has been criticized heavily on multiple grounds in recent years (e.g., Fritz \& Mackinnon, 2007; Mackinno et al., 2002). Most notably, "it is not based on a quantification of the very thing it is attempting to test-the mediation effect. Rather, the existence of an indirect effect is inferred logically by the outcome of a set of hypothesis tests" (Hayes, 2009 p.410). For the Sobel test, its major flaw is that it assumes the sampling distribution of the indirect effect is normal (Hayes, 2009). However, the sampling distribution of the indirect effect tends to be asymmetric with nonzero skewness and kurtosis (Stone \& Sobel, 1990).

In contrast, using the bias corrected bootstrapping confidence interval technique on indirect effect to test for mediation effects can address the above criticisms as it tests the indirect effect directly without assuming a normally distributed sampling. Technically, the indirect effects of OS to OSC to GSC (H4) and OS to SSTL to GSC (H7) were examined by bootstrapping 5000 times in AMOS 24. 
Bootstrapping is a resampling method to construct a confidence interval for the indirect effects. Table 7 presents the results of bootstrapping the indirect effects. Significant indirect effect of OS to OSC to $\operatorname{GSC}(\beta=0.134, p=0.002)(\mathrm{H} 4)$ and OS to SSTL to $\operatorname{GSC}(\beta=0.239, p=0.001)(\mathrm{H} 7)$ were found, suggesting that OS affects SCG through the mediators SSTL and OSC.

[Table 7. Mediators between organizational support (OS) and group-level safety climate (GSC)]

\section{Moderation}

The moderation effect represents whether and to what degree one certain variable influences the size of another variable's effect on a third variable. In the study, a significant moderation effect by OS on the relationship between CS and GSC was found through the interaction term (OS X CS) in the structural model $(\beta=0.129, p=0.017)$. This suggests that OS positively strengthens the relationship between CS and GSC, supporting H9. To foster explicit understanding of the moderation interaction effect, the interaction graph of Figure 3 signify the moderator (OS)'s high and low positions, respectively. The results as shown in Figure 3 indicate that an increase in OS strengthens the effect of CS on cultivating GSC.

[Fig. 3. Moderation effect of OS on the relationship between CS and GSC]

\section{DISCUSSION}

Group-level safety climate (GSC) has been found as a proximal antecedent to workers' safety behaviors (e.g., Zohar and Luria, 2005; Lingard et al., 2010). Therefore, a better understanding of GSC's mechanisms and its drivers will enable construction contractors to develop more targeted interventions to improve GSC. In particular, the results of this study confirm that organizational support (OS) cascades down to cultivate GSC through the mediation role of organization-level safety climate (OSC) and supervisory safety-specific transformation leadership (SSTL), as well as through moderating the relationship between co-worker support (CS) and GSC

Although OS has been identified as an important factor in cultivating GSC in previous studies (Wallace et al. 2006; DeJoy et al. 2010), this study shows that there is no direct effect of OS on GSC. 
Instead, OS has a significant indirect effect on GSC through the mediating effects of OSC and supervisory SSTL, and a moderation effect on the relationship between CS and GSC. The results suggest that the cultivation of a positive work-group safety climate requires efforts and interventions at a broader organizational level. Many safety-related interventions and campaigns have only targeted the local-workplace level or even individual level. There is a need to move to examine the critical question of how broader contextual factors influence the development of a safety environment and subsequently safety norms and behaviors (Hofmann et al. 2017). In addition, this research indicates that each level of an organization plays a part in ensuring a positive safety climate within workgroups, but safety support at the organizational level has a fundamental and cascading influence. This result aligns with recent research that safety commitment at the top management level shapes how safety is enacted at lower organizational levels, which ultimately influence safety performance in construction projects (Gao et al. 2016). The study also illustrates that organizational support for safety provides important clues for supervisors about their safety roles and responsibilities, and directs supervisors to ensure high levels of safety within their workgroups through effective transformational leadership behaviors. These results are aligned with Conchie et al. (2013) who suggest that supervisors' engagement in safety leadership is dependent on organizational environment. In practice, top management of an organization can demonstrate their support for safety through various ways, such as considering safety when making organizational decisions, ensuring sufficient resources (both monetary and human resources) for safety, and publicly recognizing safety improvements and successes. Meanwhile, management should make their supportive actions visible to employees to enhance positive safety perceptions at the organizational and subsequently group level. Previous research also suggests that top management can demonstrate their safety support through a participatory approach, e.g. actively involving in safety-related activities, visiting workplace to check safety conditions, and communicating with workers regarding safety objectives (Jitwasinkul et al. 2016).

The coefficient of determination $\left(\gamma^{2}\right)$ in this study is $56 \%$, showing the hypothesized model explained a substantial degree of variance of GSC. By examining the direct effects of all independent 
variables in the model, it is noticed that SSTL has the highest beta coefficient (0.555). This implies that SSTL has the strongest impact on GSC compared to other variables. This finding aligns with previous research results that supervisory leadership behaviors act as a more powerful antecedent to workers' safety perceptions and behaviors than organizational expectations (Zohar and Luria, 2005; Lingard et al. 2012). It is also consistent with previous research conducted in the construction project context, where supervisory safety behaviours have a significant impact on workgroup safety climate and workers' safety behaviour (Fang et al. 2015). In project-based work environments such as in the construction industry, employees normally have limited direct contact with senior management, while they interact with their supervisors on a daily basis. Therefore, employees are more likely to be affected by their immediate supervisors. Research evidence also indicates that effective supervisory leadership can help to maintain a positive group safety climate in construction projects even under the circumstance when perceptions of the organizational safety climate may have deteriorated (Zhang et al. 2018). Through the frequent interactions between supervisors and employees, transformational supervisors are able to develop strong safety norms and a positive safety environment within workgroups through consistently prioritizing safety on different occasions, displaying a supportive leadership style and proactively talking about safety with employees (Shen et al. 2017). Mullen and Kelloway (2009) suggested that transformational leadership training programs can be useful in developing supervisory capability in leadership, which leads to improved group-level safety climate.

Consistent with previous studies (Shen et al. 2017; Zohar, 2000), the statistical results in this study provide support that group safety climate and supervisory leadership are two conceptually distinct constructs. Safety climate is workers' perceptions of relative emphasis that a supervisor places on competing goals (e.g. production speed and safety) (Zohar, 2000). Workers form their perceptions through observing the patterns in supervisors' safety responses in relation to implementing safety policies and procedures across different circumstances. In contrast, perceptions of supervisory leadership are more related to behavioral attributes that remain unchanged across occasions (e.g. a specific leadership style) (Zohar, 2000). In addition, supervisory leadership is more relationship-based and reflects the quality and effectiveness of interpersonal relationships or exchanges, while group 
safety climate is more commitment-based and indicates the consistency in supervisors' safety responses (Zohar and Luria, 2005; Shen et al. 2017). Safety climate and supervisory leadership are two independent but related aspects of supervisory behavior (Zohar, 2000).

Apart from the significant mediation effects found in the study, a significant moderation effect of OS on the relationship between CS on GSC was also discovered. Consistent with previous research (Brondino et al. 2012; Lingard et al. 2011), this research indicates that co-workers play a crucial role in the formation of positive group-level safety climate. Co-workers are in the immediate work environment of employees and have frequent interactions with the employees. Co-workers' support for safety significantly contributes to the establishment of safety norms and standards in the workgroups and provides social cues to employees about expected safety attitudes and behaviors (Tucker et al. 2008; Turner et al. 2010). Previous research shows that when the group norms are internalized by workers, they have significant influence on workers standards regarding safety behavior (Choi et al. 2017). In addition, the research results suggest that the influence of co-workers' support on group-level safety climate would be strengthened if top management demonstrates support for safety and emphasizes the importance of safety at the organizational level. This, again, highlights the important role of organizational contextual factors, which shape overall working norms through ambient stimuli and provide overarching guidance to what behaviors will be valued (Wallace et al. 2006). To sum up, this research reveals that organizational support cascades down to influence grouplevel safety climate through various pathways.

\section{LIMITATIONS AND FUTURE RESEARCH}

This study provides some important insights into the mechanism of how organizational support cultivates multi-level safety climate with co-worker support and supervisory safety-specific transformation leadership, but there are limitations to be acknowledged. First, a single large construction organization was examined in this study with the aim to control the confounding effect on intra-organizational differences such as culture and structure. The results may not be generalizable to other small and medium size construction organizations. Future research should be conducted to test 
the applicability of the model to other companies with different sizes within the same sector or in different engineering sectors. Examining the research model within a border range of companies and sectors would help reveal the common patterns relating to the role of organizational support in the formation of group level safety climate, as well as differences attributed to different company sizes or industry sector characteristics. Second, as the data of the study was collected from the same individuals, the relationships among the variables may be confounded by common method bias. Although the longitudinal research design as well as statistical control for stable differences in social desirability were implemented to minimize the effects of common method bias, it is recommended that multiple sources should be used for each data point in future work so as to solve the issue fundamentally. Finally, a limitation relates to the representativeness of the sample. Similar to other longitudinal studies, attribution could be a problem since the longitudinal sample may over-represent highly committed employees who care about the subject matter than others (Neal \& Griffin, 2006).

\section{CONCLUSION}

Longitudinal studies on the antecedents, mediators and moderators of multilevel safety climate in the construction industry are rare. The current study spans a 2-year period during which organizational support (OS) and co-worker support (CS) were measured prior to the measure of safetyspecific transformational leadership (SSTL), organisational-level safety climate (OSC) and grouplevel safety climate (GSC). The current study, therefore, has made a contribution to the body of knowledge by providing stronger evidence on the direction of causation and the underlying mechanism than previous studies within the field. Consequently, it could enable the industry develop more targeted interventions to improve GSC. In contrast with the findings of Wallace et al. (2006) and DeJoy et al. (2010), the results of this study reveal that OS does not directly affect GSC. Instead, OS cascades down to cultivate GSC through the mediation role of OSC and SSTL, as well as through moderating the relationship between CS and GSC.

The results of this study have both theoretical and practical implications. The study goes beyond previous research that has identified associations between safety climate and safety related 
outcomes, by exploring various antecedents to GSC and revealing mechanisms through which the antecedents influence GSC. This research enables organizations in construction as well as broader engineering sectors to understand how organizational contextual factors and local workgroup factors work together to shape GSC, which provides behavioural guidance to workers and subsequently improves safety performance. The research findings provide evidence for construction organizations to invest in targeted interventions to enhance OS for safety, improve supervisory SSTL, strengthen OSC, and encourage CS, because all these aspects interact with each other to collectively cultivate a positive GSC. In particular, construction organizations need to focus on developing safety supportive actions at the organizational level as the research indicates that OS has a fundamental and cascading influence on GSC. Examples of such supportive actions may include considering safety when making production decisions, ensuring sufficient resources and training are provided for safety matters, and publicly recognizing safety improvements and best practices. This research statistically demonstrates that supervisory SSTL is a major contributing factor to GSC. Supervisors play an important role in providing subordinates with relevant safety support through daily interactions such as showing subordinates the safest way to do things at work and making sure appropriate rewards for achieving safety targets on the job are provided. The importance of supervisory safety leadership revealed in this research urges construction organizations to provide SSTL training programs to their supervisors and front-line managers. As Mullen and Kelloway (2009) illustrated, SSTL training programs are more useful than general leadership training programs in terms of developing supervisory capability in promoting safety in workplaces. In addition, co-workers' safety support also plays an important role in creating a positive safety climate in workgroup. Co-workers' safety support may further generate workers' perceived obligation to care about their co-workers' safety or intervene when co-workers are in unsafe conditions (Stackhouse \& Turner 2019). The research result suggests that intervention or training programs that aim to enhance employees' sense of safety responsibility and caring for others' safety will be helpful in creating a safer workplace.

The research also contributes to the domain of general management in engineering through providing useful implications to other high-risk industries where safety is a key priority, such as oil 
and gas, mining, infrastructure and process industries. Within these industry, frontline operations are normally undertaken by semi-autonomous workgroups, which are led by workgroup supervisors with supervisory discretions and meanwhile situated in specific organizational contexts. The research results suggest that management in these industries should be aware that safety is the outcome of interactions of acts and practices at multiple organizational levels and therefore a cross-organizational effort is required to ensure safety at the frontline level. Particularly, the safety support at the organizational level helps to create a social context where the importance of safety is established, and the importance is further reinforced through supervisory safety leadership and co-workers' safety interactions.

\section{DATA AVAILAIBLITY STATEMENT}

All data, models, or code generated or used during the study are available from the corresponding author by request.

\section{REFERENCES}

Alruqi, W. M., Hallowell, M. R., \& Techera, U. (2018). Safety climate dimensions and their relationship to construction safety performance: A meta-analytic review. Safety science, 109, $165-173$.

Barling, J., Loughlin, C., \& Kelloway, E. K. (2002). "Development and test of a model linking safetyspecific transformational leadership and occupational safety." Journal of applied psychology, 87(3), 488-496.

Baron, R. M., \& Kenny, D. A. (1986). "The moderator-mediator variable distinction in social psychological research: Conceptual, strategic, and statistical considerations." Journal of personality and social psychology, 51(6), 1173-1182.

Bass, B. M. (1985). Leadership and performance beyond expectations, Free Press, New York, USA.

Blau, P. (2017). Exchange and power in social life, Routledge, New York, USA.

Brondino, M., Silva, S. A., \& Pasini, M. (2012). "Multilevel approach to organizational and group safety climate and safety performance: Co-workers as the missing link.” Safety science, 50(9), $1847-1856$. 
Chen, Y., McCabe, B., \& Hyatt, D. (2017). "Impact of individual resilience and safety climate on safety performance and psychological stress of construction workers: a case study of the Ontario construction industry." Journal of safety research, 61, 167-176.

Chiaburu, D. S., \& Harrison, D. A. (2008). "Do peers make the place? Conceptual synthesis and metaanalysis of coworker effects on perceptions, attitudes, OCBs, and performance." Journal of Applied Psychology, 93(5), 1082-1103.

Choi, B., Ahn, S., \& Lee, S. (2017). “Construction workers' group norms and personal standards regarding safety behavior: Social identity theory perspective." Journal of management in engineering, 33(4), 04017001-11.

Clarke, S. (2013). "Safety leadership: A meta-analytic review of transformational and transactional leadership styles as antecedents of safety behaviours." Journal of Occupational and Organizational Psychology, 86(1), 22-49.

Conchie, S. M., Moon, S., \& Duncan, M. (2013). “Supervisors' engagement in safety leadership: Factors that help and hinder." Safety science, 51(1), 109-117.

Curcuruto, M., Griffin, M. A., Kandola, R., \& Morgan, J. I. (2018). Multilevel safety climate in the UK rail industry: A cross validation of the Zohar and Luria MSC scale. Safety science, 110, 183-194.

Dahl, Ø., \& Kongsvik, T. (2018). Safety climate and mindful safety practices in the oil and gas industry. Journal of safety research, 64, 29-36.

DeJoy, D. M., Della, L. J., Vandenberg, R. J., \& Wilson, M. G. (2010). "Making work safer: Testing a model of social exchange and safety management." Journal of safety research, 41(2), 163171.

DeJoy, D. M., Schaffer, B. S., Wilson, M. G., Vandenberg, R. J., \& Butts, M. M. (2004). “Creating safer workplaces: assessing the determinants and role of safety climate." Journal of safety research, 35(1), 81-90.

Dierdorff, E. C., Rubin, R. S., \& Morgeson, F. P. (2009). The milieu of managerial work: An integrative framework linking work context to role requirements. Journal of Applied Psychology, 94(4), 972-988. 
Donaldson, S. I., \& Grant-Vallone, E. J. (2002). “Understanding self-report bias in organizational behavior research." Journal of business and Psychology, 17(2), 245-260.

Eisenberger, R., Huntington, R., Hutchison, S., \& Sowa, D. (1986). “Perceived organizational support." Journal of Applied psychology, 71(3), 500-507.

Erdogan, B., \& Enders, J. (2007). "Support from the top: Supervisors' perceived organizational support as a moderator of leader-member exchange to satisfaction and performance relationships." Journal of applied psychology, 92(2), 321-330.

Fang, D., Wu, C., \& Wu, H. (2015). Impact of the supervisor on worker safety behavior in construction projects. Journal of Management in Engineering, 31(6), 04015001.

Fornell, C., \& Larcker, D. F. (1981). "Structural equation models with unobservable variables and measurement error: Algebra and statistics.” Journal of Marketing Research, 18(3), 382-388.

Fritz, M. S., \& MacKinnon, D. P. (2007). "Required sample size to detect the mediated effect." Psychological science, 18(3), 233-239.

Gao, R., Chan, A. P. C., Utama, W. P., \& Zahoor, H. (2016). "Multilevel Safety Climate and Safety Performance in the Construction Industry: Development and Validation of a Top-Down Mechanism." International Journal of Environmental Research and Public Health, 13(11), 1100.

Gillen, M., Baltz, D., Gassel, M., Kirsch, L., \& Vaccaro, D. (2002). "Perceived safety climate, job demands, and coworker support among union and nonunion injured construction workers." Journal of safety research, 33(1), 33-51.

Glendon, A. I., \& Stanton, N. A. (2000). "Perspectives on safety culture." Safety science, 34(1-3), 193214.

Guldenmund, F. W. (2000). "The nature of safety culture: a review of theory and research." Safety science, 34(1-3), 215-257.

Gyekye, SA \& Salminen, S (2007). "Workplace safety perceptions and perceived organizational support: Do supportive perceptions influence safety perceptions?" , International Journal of Occupational Safety and Ergonomics, 13(2), 189-200. 
Hair, J. F., Black, W. C., Babin, B. J., \& Anderson, R. E. (2013). Multivariate data analysis: Pearson new international edition. Essex: Pearson Education Limited, USA.

Hayes, A. F. (2009). Beyond Baron and Kenny: "Statistical mediation analysis in the new millennium." Communication monographs, 76(4), 408-420.

Hayes, A. F., \& Scharkow, M. (2013). "The relative trustworthiness of inferential tests of the indirect effect in statistical mediation analysis: does method really matter?" Psychological Science, 24(10), 1918-1927.

He, Q., Dong, S., Rose, T., Li, H., Yin, Q., \& Cao, D. (2016). "Systematic impact of institutional pressures on safety climate in the construction industry." Accident Analysis \& Prevention, 93, $230-239$.

Hofmann, D. A., Burke, M. J., \& Zohar, D. (2017). 100 years of occupational safety research: From basic protections and work analysis to a multilevel view of workplace safety and risk. Journal of applied psychology, 102(3), 375-388.

Hoffmeister, K., Gibbons, A. M., Johnson, S. K., Cigularov, K. P., Chen, P. Y., \& Rosecrance, J. C. (2014). The differential effects of transformational leadership facets on employee safety. Safety science, 62, 68-78.

Hooper, D., Coughlan, J., \& Mullen, M. (2008). "Structural equation modelling: Guidelines for determining model fit." e-journal of Business Research Methods, Articles, 2.

Huang, Y. H., Lee, J., McFadden, A. C., Rineer, J., \& Robertson, M. M. (2017). "Individual employee's perceptions of "Group-level Safety Climate”(supervisor referenced) versus “Organization-level Safety Climate”(top management referenced): Associations with safety outcomes for lone workers." Accident Analysis \& Prevention, 98, 37-45.

Jitwasinkul, B., Hadikusumo, B. H. W., \& Memon, A. Q. (2016). "A Bayesian Belief Network model of organizational factors for improving safe work behaviors in Thai construction industry." Safety science, 82, 264-273.

Kelloway, E. K., Mullen, J., \& Francis, L. (2006). "Divergent effects of transformational and passive leadership on employee safety." Journal of occupational health psychology, 11(1), 76. 
Kline, R. B. (2015). Principles and practice of structural equation modeling, Guilford publications, New York.

Kozlowski, S. W. J., \& Klein, K. J. (2000). A multilevel approach to theory and research in organizations: Contextual, temporal, and emergent processes. In K. J. Klein \& S. W. J. Kozlowski (Eds.), Multilevel theory, research, and methods in organizations: Foundations, extensions, and new directions (pp. 3-90), Jossey-Bass, San Francisco. USA.

Lingard, H. C., Cooke, T., \& Blismas, N. (2010). "Safety climate in conditions of construction subcontracting: a multi-level analysis." Construction Management \& Economics, 28(8), 813825 .

Lingard, H., Cooke, T., \& Blismas, N. (2011). "Coworkers' response to occupational health and safety: An overlooked dimension of group-level safety climate in the construction industry?" Engineering, construction and architectural management, 18(2), 159-175.

Lingard, H., Cooke, T., \& Blismas, N. (2012). "Do Perceptions of Supervisors' Safety Responses Mediate the Relationship between Perceptions of the Organizational Safety Climate and Incident Rates in the Construction Supply Chain?" Journal of Construction Engineering \& Management, 138(2), 234-241.

MacKinnon, D. P., Lockwood, C. M., Hoffman, J. M., West, S. G., \& Sheets, V. (2002). “A comparison of methods to test mediation and other intervening variable effects." Psychological methods, 7(1), 83.

Mearns, K. J., \& Reader, T. (2008). “Organizational support and safety outcomes: An un-investigated relationship?" Safety science, 46(3), 388-397.

Mullen, J. E., \& Kelloway, E. K. (2009). "Safety leadership: A longitudinal study of the effects of transformational leadership on safety outcomes." Journal of occupational and organizational psychology, 82(2), 253-272.

Mueller, L., DaSilva, N., Townsend, J., \& Tetrick, L. (1999). “An empirical evaluation of competing safety climate measurement models." Society for Industrial and Organizational Psychology. 
Neal, A., \& Griffin, M. A. (2006). A study of the lagged relationships among safety climate, safety motivation, safety behavior, and accidents at the individual and group levels. Journal of applied psychology, 91(4), 946.

Podsakoff, P. M., MacKenzie, S. B., Lee, J. Y., \& Podsakoff, N. P. (2003). “Common method biases in behavioral research: A critical review of the literature and recommended remedies." Journal of applied psychology, 88(5), 879 -903.

Pousette, A., Larsson, S., \& Törner, M. (2008). "Safety climate cross-validation, strength and prediction of safety behaviour." Safety science, 46(3), 398-404.

Schein, E. H. (1985). Organizational culture and leadership. Jossey-Bass, San Francisco, USA

Shen, Y., Ju, C., Koh, T., Rowlinson, S., \& Bridge, A. (2017). “The impact of transformational leadership on safety climate and individual safety behavior on construction sites." International journal of environmental research and public health, 14(1), 45.

Sobel, M. E. (1986). "Some new results on indirect effects and their standard errors in covariance structure models."'Sociological methodology. 16, 159-186.

Stackhouse, M., \& Turner, N. (2019). How do organizational practices relate to perceived system safety effectiveness? Perceptions of safety climate and co-worker commitment to safety as workplace safety signals. Journal of Safety Research, 70, 59-69.

Stone, C. A., \& Sobel, M. E. (1990). “The robustness of estimates of total indirect effects in covariance structure models estimated by maximum." Psychometrika, 55(2), 337-352.

Strahan, R., \& Gerbasi, K. C. (1972). "Short, homogeneous versions of the Marlow-Crowne Social Desirability Scale.” Journal of Clinical Psychology, 28(2), 191-193.

The Center for Construction Research and Training (2017). The construction chart book: The US construction industry and its workers. Cpwr-The Center for Construction Research and Training, Maryland, USA.

Tucker, S., Chmiel, N., Turner, N., Hershcovis, M. S., \& Stride, C. B. (2008). "Perceived organizational support for safety and employee safety voice: The mediating role of coworker support for safety.” Journal of occupational health psychology, 13(4), 319. 
Turner, N., Chmiel, N., Hershcovis, M. S., \& Walls, M. (2010). "Life on the line: Job demands, perceived co-worker support for safety, and hazardous work events." Journal of occupational health psychology, 15(4), 482-493

U.S. Bureau of Labor Statistics (BLS). (2017). Fatal occupational injuries by event or exposure for all fatal injuries and major private industry sector, United States, 2017. Retrieved January 3, 2019, from https://www-bls-gov.manchester.idm.oclc.org/iif/oshwc/cfoi/cftb0321.htm

Wallace, J. C., Popp, E., \& Mondore, S. (2006). "Safety climate as a mediator between foundation climates and occupational accidents: A group-level investigation." Journal of applied psychology, 91(3), 681-688.

Williams, J., \& MacKinnon, D. P. (2008). "Resampling and distribution of the product methods for testing indirect effects in complex models." Structural Equation Modeling: A Multidisciplinary Journal, 15(1), 23-51.

Willis, S., Clarke, S., \& O'Connor, E. (2017). “Contextualizing leadership: Transformational leadership and Management-By-Exception-Active in safety-critical contexts.” Journal of Occupational and Organizational Psychology, 90(3), 281-305.

Zhang, R. P., Lingard, H., \& Nevin, S. (2015). "Development and validation of a multilevel safety climate measurement tool in the construction industry." Construction management and economics, 33(10), 818-839.

Zhang, R. P., Pirzadeh, P., Lingard, H., \& Nevin, S. (2018). "Safety climate as a relative concept: Exploring variability and change in a dynamic construction project environment." Engineering, Construction and Architectural Management, 25(3), 298-316.

Zohar, D. (1980). "Safety climate in industrial organizations: theoretical and applied implications." Journal of Applied Psychology, 65(1), 96.

Zohar, D. (2000). “A group-level model of safety climate: testing the effect of group climate on microaccidents in manufacturing jobs." Journal of applied psychology, 85(4), 587-596.

Zohar, D. (2002a). "Modifying supervisory practices to improve subunit safety: a leadership-based intervention model.” Journal of Applied psychology, 87(1), 156. 
Zohar, D. (2002b). “The effects of leadership dimensions, safety climate, and assigned priorities on minor injuries in work groups.” Journal of organizational behavior, 23(1), 75-92.

Zohar, D., \& Luria, G. (2005). “A multilevel model of safety climate: cross-level relationships between organization and group-level climates.” Journal of Applied Psychology, 90(4), 616628.

Zohar, D. (2010). “Thirty years of safety climate research: Reflections and future directions.” Accident Analysis \& Prevention, 42(5), 1517-1522.

\section{FIGURES AND TABLES}

Fig. 1. Statistics on the 284 valid respondents in terms of tenure at the company, work experience in the industry, education, and gender

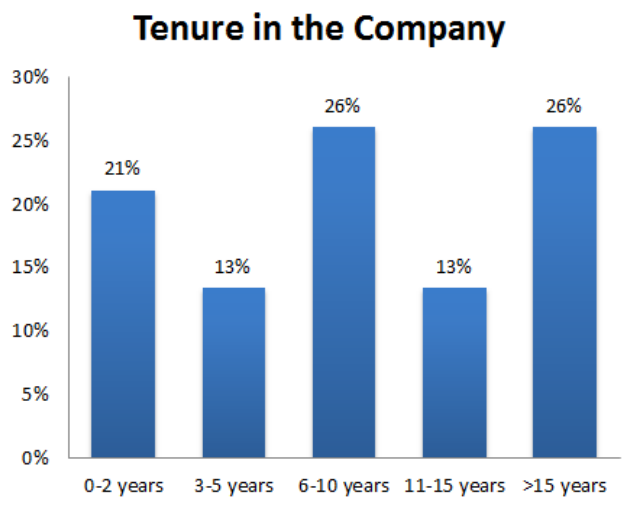

Education

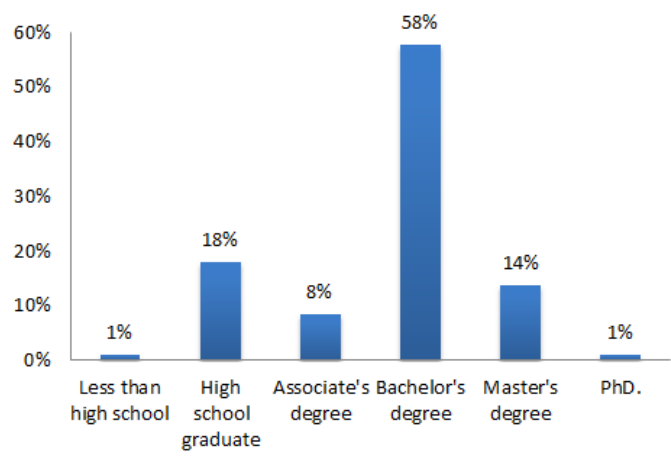

Work Experience in Construction

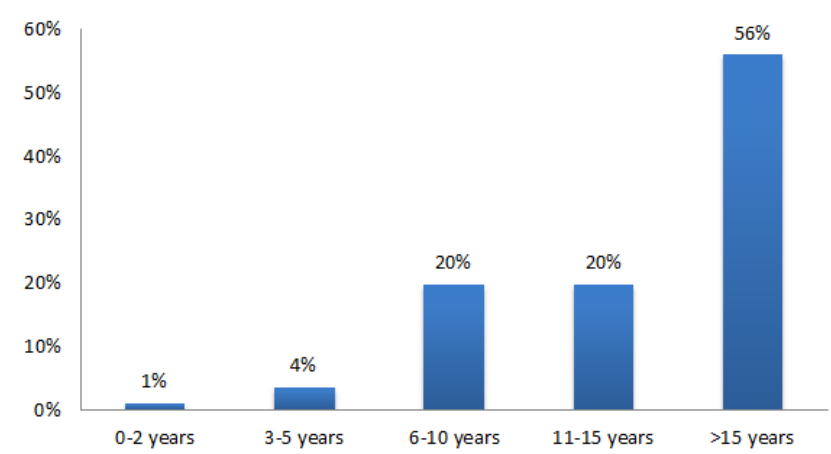

Gender

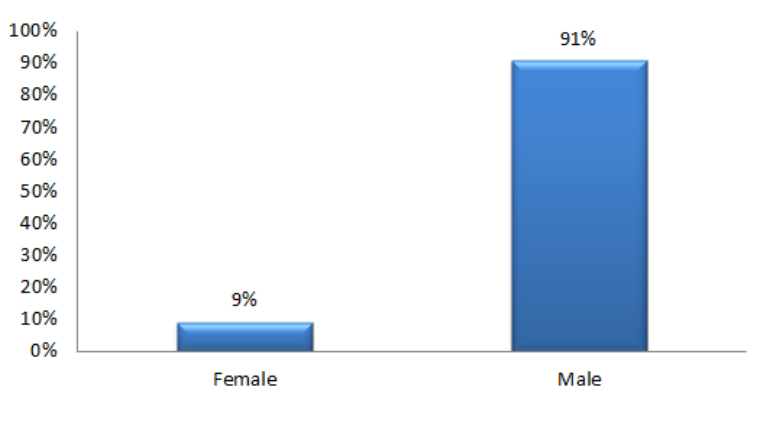


843

844

845

846

847

848

849

850

851

852

853

854

855

856

857

858

859

860

861

Fig. 2. Hypothesized model estimation results (note: $* * * p<0.001, * * p=0.001-0.010, * p=0.011-0.049$ )

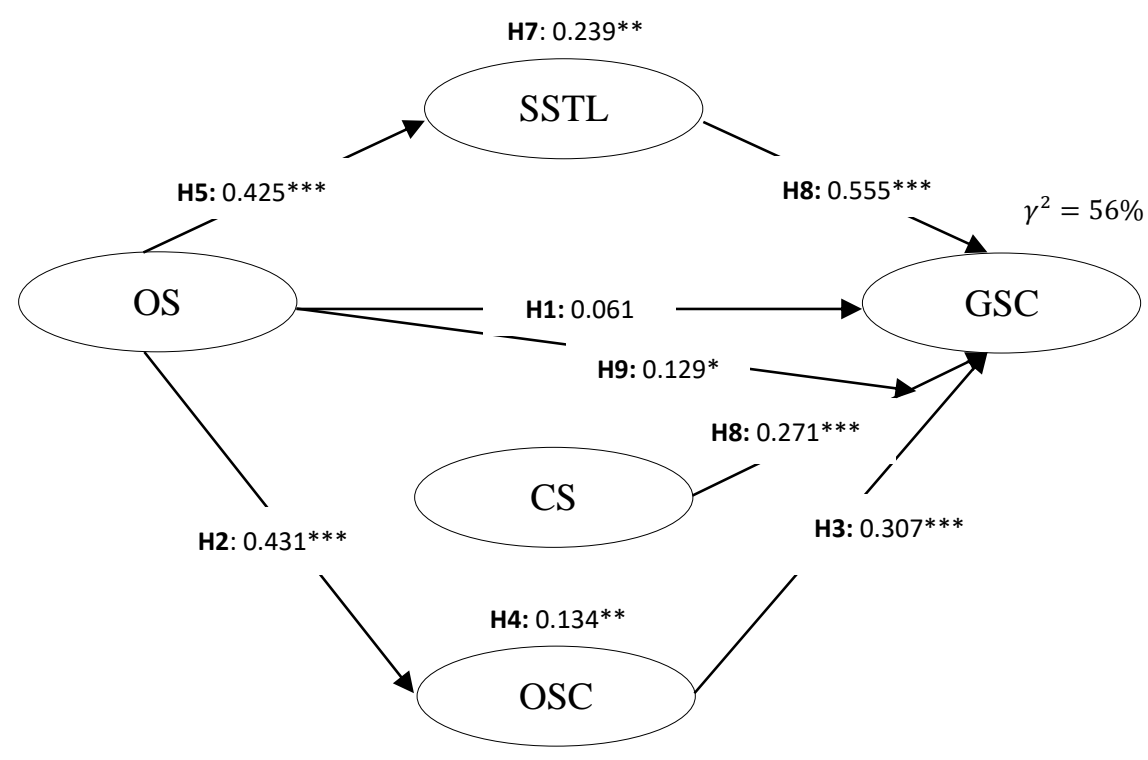

Fig. 3. Moderation effect of organisational support (OS) on co-worker support (CS) and group-level safety climate (GSC).

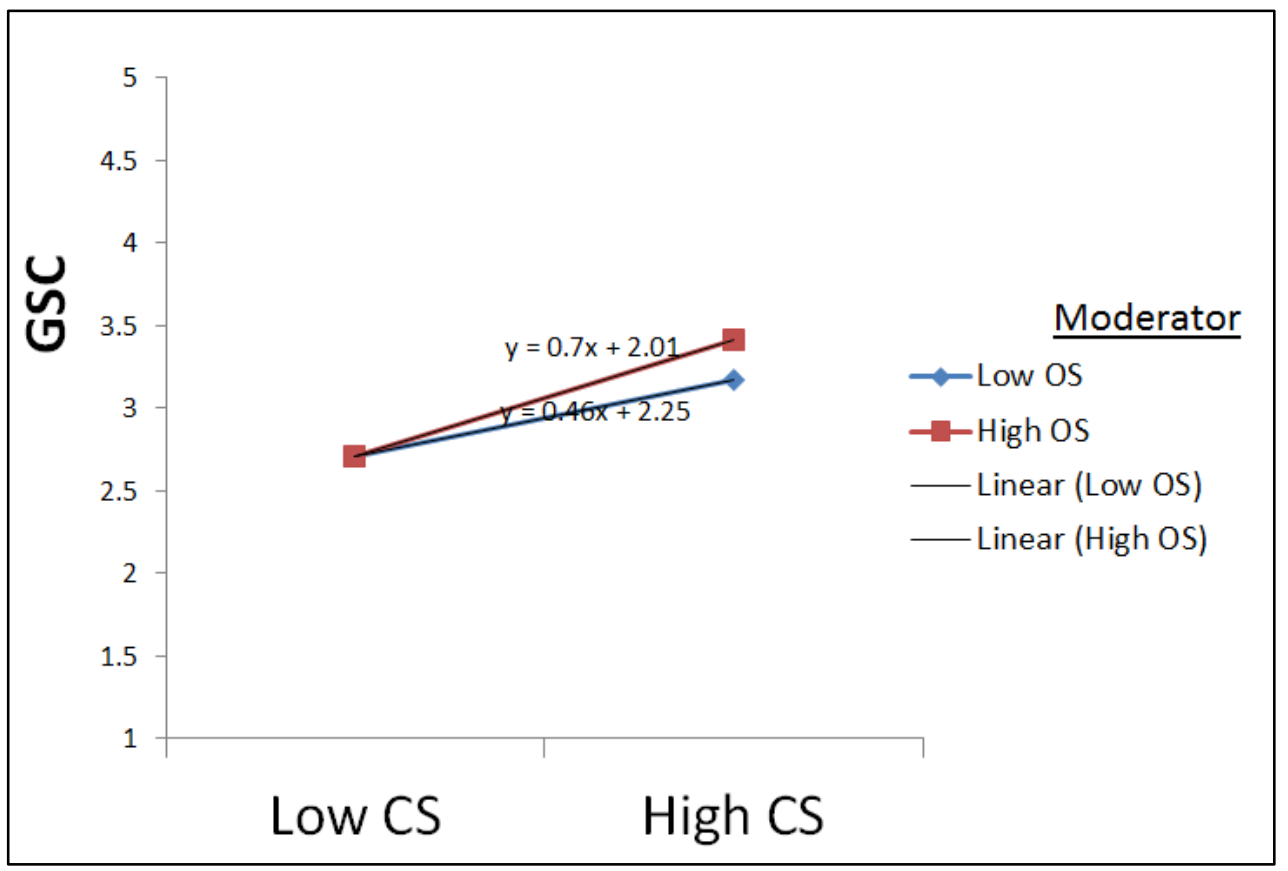


Table 1. Measurement scales

\begin{tabular}{|c|c|c|c|}
\hline Variable & Scale & Point of Scales & Items \\
\hline \multirow{3}{*}{ Organizational Support (OS) } & \multirow{3}{*}{$\begin{array}{c}\text { Management } \\
\text { Attitude Toward } \\
\text { Safety Scale, } \\
\text { Mueller et al. } \\
\text { (1999) }\end{array}$} & \multirow{3}{*}{$\begin{array}{l}\text { 5-point scale } \\
\text { (strongly } \\
\text { disagree to } \\
\text { strongly agree) }\end{array}$} & 1. The top management gets personally involved in safety activities \\
\hline & & & 2. The top management is willing to invest money and effort to improve safety. \\
\hline & & & 3. The top management seems to care about my safety. \\
\hline \multirow{10}{*}{$\begin{array}{c}\text { Safety Specific } \\
\text { Transformational Leadership } \\
\text { (SSTL) }\end{array}$} & \multirow{10}{*}{$\begin{array}{l}\text { Safety Specific } \\
\text { Transformational } \\
\text { Leadership } \\
\text { Scale, Barling et } \\
\text { al. (2002) }\end{array}$} & \multirow{10}{*}{$\begin{array}{l}\text { 5-point scale } \\
\text { (not at all to } \\
\text { always) }\end{array}$} & 1. My day-to-day supervisor expresses satisfaction when I perform the job safely. \\
\hline & & & $\begin{array}{l}\text { 2. My day-to-day supervisor makes sure that I receive appropriate rewards for } \\
\text { achieving safety targets on the job. }\end{array}$ \\
\hline & & & $\begin{array}{l}\text { 3. My day-to-day supervisor provides continuous encouragement to me to do my } \\
\text { job safely. }\end{array}$ \\
\hline & & & $\begin{array}{l}\text { 4. My day-to-day supervisor shows determination to maintain a safe work } \\
\text { environment. }\end{array}$ \\
\hline & & & 5. My day-to-day supervisor suggests new ways of doing our jobs more safely. \\
\hline & & & $\begin{array}{l}\text { 6. My day-to-day supervisor encourages me to express my ideas and opinions } \\
\text { about safety at work. }\end{array}$ \\
\hline & & & $\begin{array}{l}\text { 7. My day-to-day supervisor talks about his or her values and beliefs regarding the } \\
\text { importance of safety. }\end{array}$ \\
\hline & & & $\begin{array}{l}\text { 8. My day-to-day supervisor behaves in a way that displays a commitment to a } \\
\text { safe workplace. }\end{array}$ \\
\hline & & & $\begin{array}{l}\text { 9. My day-to-day supervisor spends time showing me the safest way to do things } \\
\text { at work. }\end{array}$ \\
\hline & & & 10. My day-to-day supervisor listens to my concerns about safety on the job. \\
\hline
\end{tabular}




\begin{tabular}{|c|c|c|c|}
\hline \multirow{3}{*}{ Co-worker Support (CS) } & \multirow{3}{*}{$\begin{array}{c}\text { Management } \\
\text { Attitude Toward } \\
\text { Safety Scale, } \\
\text { Mueller et al. } \\
\text { (1999) }\end{array}$} & \multirow{3}{*}{$\begin{array}{l}\text { 5-point scale } \\
\text { (strongly } \\
\text { disagree to } \\
\text { strongly agree) }\end{array}$} & 1. People in my work group expect each other to behave safely. \\
\hline & & & $\begin{array}{l}\text { 2. People in my work group emphasise working safety and make sure other do the } \\
\text { same. }\end{array}$ \\
\hline & & & 3. People in my work group remind each other to follow safety regulations. \\
\hline \multirow{10}{*}{$\begin{array}{l}\text { Organizational-Level Safety } \\
\text { Climate (OSC) }\end{array}$} & \multirow{10}{*}{$\begin{array}{l}\text { Organizational- } \\
\text { Level Safety } \\
\text { Climate } \\
\text { Questionnaire; } \\
\text { Zohar and Lucia } \\
\quad \text { (2005) }\end{array}$} & \multirow{10}{*}{$\begin{array}{l}\text { 5-point scale } \\
\text { (completely } \\
\text { disagree to } \\
\text { completely } \\
\text { agree) }\end{array}$} & $\begin{array}{l}\text { 1. The senior management reacts quickly to solve problems when notified about } \\
\text { safety hazards. }\end{array}$ \\
\hline & & & $\begin{array}{l}\text { 2. The senior management insists on thorough and regular safety audits and } \\
\text { inspections. }\end{array}$ \\
\hline & & & $\begin{array}{l}\text { 3. The senior management tries to continually improve safety levels in each } \\
\text { department. }\end{array}$ \\
\hline & & & 4. The senior management provides all the equipment needed to do the job safety. \\
\hline & & & $\begin{array}{l}\text { 5. The senior management is strict about working safely when work falls behind } \\
\text { schedule. }\end{array}$ \\
\hline & & & 6. The senior management quickly corrects any safety hazard (even if it's costly). \\
\hline & & & $\begin{array}{l}\text { 7. The senior management provides detailed safety reports to workers (e.g., } \\
\text { injuries, near accidents). }\end{array}$ \\
\hline & & & $\begin{array}{l}\text { 8. The senior management considers a person's safety behavior when moving or } \\
\text { promoting people. }\end{array}$ \\
\hline & & & $\begin{array}{l}\text { 9. The senior management requires each manager to help improve safety in } \\
\text { his/her department. }\end{array}$ \\
\hline & & & $\begin{array}{l}\text { 10. The senior management invests a lot of time and money in safety training for } \\
\text { workers. }\end{array}$ \\
\hline
\end{tabular}




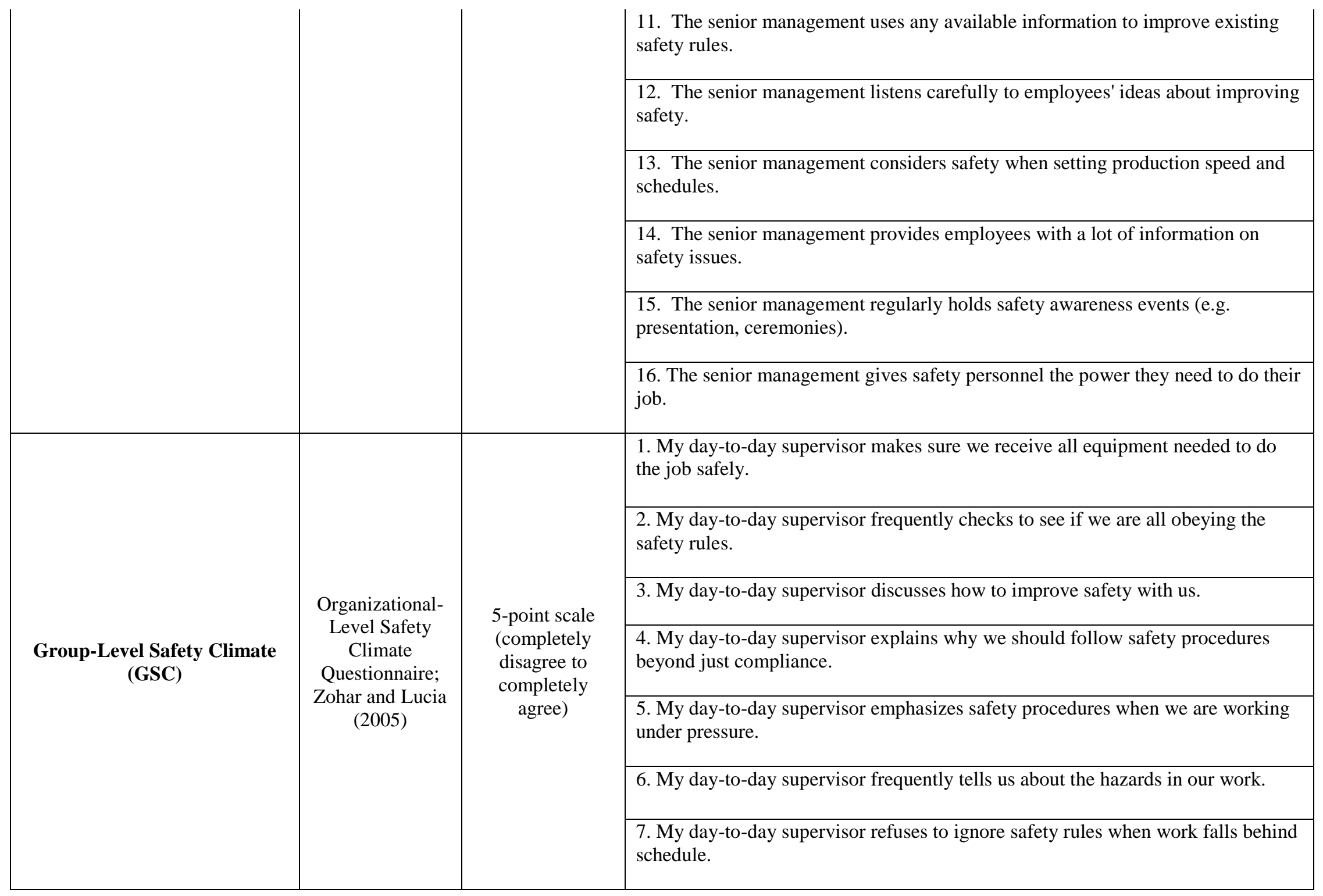




\begin{tabular}{|c|c|c|c|}
\hline & & & $\begin{array}{l}\text { 8. My day-to-day supervisor is strict about working safely when we are tired or } \\
\text { stressed. }\end{array}$ \\
\hline & & & 9. My day-to-day supervisor reminds us to work safely. \\
\hline & & & $\begin{array}{l}\text { 10. My day-to-day supervisor makes sure we follow all the safety rules (not just } \\
\text { the most important ones). }\end{array}$ \\
\hline & & & $\begin{array}{l}\text { 11. My day-to-day supervisor insists that we obey safety rules when fixing } \\
\text { equipment or machines. }\end{array}$ \\
\hline & & & $\begin{array}{l}\text { 12. My day-to-day supervisor says a "good word" to subordinates who pay special } \\
\text { attention to safety. }\end{array}$ \\
\hline & & & 13. My day-to-day supervisor is strict about safety in all the phases of our work. \\
\hline & & & $\begin{array}{l}\text { 14. My day-to-day supervisor spends time teaching us to identify safety issues } \\
\text { before they arise. }\end{array}$ \\
\hline & & & $\begin{array}{l}\text { 15. My day-to-day supervisor frequently talks about safety issues throughout the } \\
\text { work week. }\end{array}$ \\
\hline & & & $\begin{array}{l}\text { 16. My day-to-day supervisor emphasizes the importance of using protective } \\
\text { equipment on the construction site. }\end{array}$ \\
\hline \multirow{5}{*}{ Social Desirability } & \multirow{5}{*}{$\begin{array}{c}\text { Marlow-Crowne } \\
\text { Social } \\
\text { Desirability } \\
\text { Scale; Strahan \& } \\
\text { Gerbasi (1972) }\end{array}$} & \multirow{5}{*}{$\begin{array}{c}\text { 5-point scale } \\
\text { (completely } \\
\text { disagree to } \\
\text { completely } \\
\text { agree) }\end{array}$} & 1. I am always willing to admit it when I make a mistake. \\
\hline & & & 2. I always try to practice what I preach. \\
\hline & & & 3. I never resent being asked to return a favor. \\
\hline & & & $\begin{array}{l}\text { 4. I have never been irked when people expressed ideas very different from my } \\
\text { own. }\end{array}$ \\
\hline & & & 5. I have never deliberately said something that hurt someone's feelings. \\
\hline
\end{tabular}


Table 2. Construct validity

(Square root of the AVE on the diagonal and correlations between two variables are below it)

\begin{tabular}{|l|c|c|c|c|c|c|c|c|}
\hline Variables & $\begin{array}{c}\text { Cronbach's } \\
\text { alpha }\end{array}$ & CR & AVE & OS & CS & SSTL & GSC & OSC \\
\hline OS & 0.821 & 0.830 & 0.622 & $\mathbf{0 . 7 8 8}$ & & & & \\
\hline CS & 0.889 & 0.896 & 0.743 & 0.667 & $\mathbf{0 . 8 6 2}$ & & & \\
\hline SSTL & 0.951 & 0.950 & 0.681 & 0.435 & 0.317 & $\mathbf{0 . 8 2 6}$ & & \\
\hline GSC & 0.960 & 0.963 & 0.652 & 0.398 & 0.438 & 0.689 & $\mathbf{0 . 8 0 8}$ & \\
\hline OSC & 0.941 & 0.936 & 0.511 & 0.446 & 0.327 & 0.473 & 0.577 & $\mathbf{0 . 7 1 5}$ \\
\hline
\end{tabular}

866 Table 3. Test results of goodness-of-fit measures for the measurement model

\begin{tabular}{lllll}
\hline Index name & Measure & Threshold & Hypothetical model & Evaluation \\
\hline Absolute fit index & $\chi 2$ test & $<0.05$ & 0.000 & Excellent \\
& RMSEA & $<0.08$ & 0.060 & Excellent \\
& RMR & $<0.05$ & 0.030 & Excellent \\
Incremental fit index & CFI & $>0.9$ & 0.910 & Good \\
& NFI & $>0.7$ & 0.837 & Excellent \\
& IFI & $>0.9$ & 0.910 & Good \\
\multirow{3}{*}{ Parsimonious fit index } & AGFI & $>0.7$ & 0.748 & Good \\
& PNFI & $>0.5$ & 0.778 & Excellent \\
& PGFI & $>0.5$ & 0.695 & Excellent \\
& PCFI & $>0.5$ & 0.856 & Excellent \\
\hline
\end{tabular}

867

Note: AGFI = adjusted goodness-of-fit index; CFI = comparative fit index; IFI = incremental fit index; $\mathrm{NFI}=$ normed fit index; $\mathrm{PCFI}$ = parsimony comparative fit index; PGFI = parsimony goodness of fit index; $\mathrm{RMR}=$ non-root mean square residual; RMSEA = root mean square error of approximation

Table 4. The results of common method bias test of the measurement model

\begin{tabular}{|l|c|c|}
\hline Variables & CR & AVE \\
\hline OS & 0.829 & 0.621 \\
\hline CS & 0.896 & 0.743 \\
\hline SSTL & 0.951 & 0.682 \\
\hline GSC & 0.963 & 0.652 \\
\hline OSC & 0.935 & 0.510 \\
\hline
\end{tabular}

Table 5. Test results of goodness-of-fit measures for the structural model

\begin{tabular}{lllll}
\hline Index name & Measure & Ideal value & Hypothetical model & Evaluatio874 \\
\hline Absolute fit index & $\chi 2$ test & $<0.05$ & 0.000 & Excellent \\
& RMSEA & $<0.08$ & 0.056 & Excellent \\
& RMR & $<0.05$ & 0.044 & Good \\
Incremental fit index & CFI & $>0.9$ & 0.904 & Good \\
& NFI & $>0.7$ & 0.817 & Excellent \\
& IFI & $>0.9$ & 0.905 & Good \\
Parsimonious fit index & AGFI & $>0.7$ & 0.747 & Good \\
& PNFI & $>0.5$ & 0.773 & Excellent \\
& PGFI & $>0.5$ & 0.700 & Excellent \\
& PCFI & $>0.5$ & 0.856 & Excellent \\
\hline
\end{tabular}

Note: AGFI = adjusted goodness-of-fit index; CFI = comparative fit index; IFI = incremental fit index; $\mathrm{NFI}=$ normed fit index $; \mathrm{PCFI}=$ parsimony comparative fit index; $\mathrm{PGFI}$ = parsimony goodness of fit index; $\mathrm{RMR}=$ non-root mean square residual; RMSEA = root mean square error of approximation 
Table 6. Test results of the hypotheses

\begin{tabular}{lccl}
\hline Hypothesis & Beta coefficient & $\boldsymbol{p}$-value & Evaluation \\
\hline Direct Effect & & & \\
H1: OS $\rightarrow$ GSC & 0.061 & 0.465 & Rejected \\
H2: OS $\rightarrow$ OSC & 0.431 & $<0.001$ & Accepted \\
H3: OSC $\rightarrow$ GSC & 0.307 & $<0.001$ & Accepted \\
H5: OS $\rightarrow$ SSTL & 0.425 & $<0.001$ & Accepted \\
H6: SSTL $\rightarrow$ GSC & 0.555 & $<0.001$ & Accepted \\
H8: CS $\rightarrow$ GSC & 0.271 & $<0.001$ & Accepted \\
Mediation and Moderation Effect & & \\
H4: OS $\rightarrow$ OSC $\rightarrow$ GSC & 0.134 & 0.002 & Accepted \\
H7: OS $\rightarrow$ SSTL $\rightarrow$ GSC & 0.239 & 0.001 & Accepted \\
H9: OS X CS $\rightarrow$ GSC & 0.129 & 0.017 & Accepted \\
\hline
\end{tabular}

881 Table 7. Mediators between organizational support (OS) and group-level safety climate (GSC)

\begin{tabular}{lllll}
\hline Mediation effect & $\begin{array}{l}\text { Beta } \\
\text { coefficient }\end{array}$ & $\begin{array}{l}\text { 95\% CI } \\
\text { Lower Bound }\end{array}$ & $\begin{array}{l}\text { 95\% CI } \\
\text { Upper Bound }\end{array}$ & P value \\
\hline H4: OS $\rightarrow$ SSTL $\rightarrow$ GSC & 0.239 & 0.165 & 0.342 & 0.001 \\
H7: OS $\rightarrow$ OSC $\rightarrow$ GSC & 0.134 & 0.066 & 0.221 & 0.002 \\
\hline
\end{tabular}

882

883

884

885 